\title{
INSTITUT DE GÉNÉTIQUE ET BIOLOGIE MOLECULAIRE ET CELLULAIRE: IGBMC
}

\author{
Pierre Chambon, M.D., Director, and Geoff Richards, Ph.D., \\ Executive Secretary
}

In the fall of 1994, Strasbourg witnessed a remarkable migration. In addition to the habitual departure of the storks of Alsace heading for warmer climes, some 400 scientists and support staff left the Institut Chimie Biologique of the Faculty of Medicine of the University Louis Pasteur to resume their research in the custom-built Institut de Génétique et Biologie Moléculaire et Cellulaire, $5 \mathrm{~km}$ to the south in the Illkirch Innovation Park (Fig. 1).

This move was the logical, but far from inevitable, consequence of the continual growth of an idea. In the late 1960s, when Pierre Chambon returned to France from Arthur Kornberg's laboratory in Stanford and set up his new group with the goal of understanding the control of gene expression in eukaryotes, it was a small but happy band of five. The group, however, soon began to expand, keeping pace with the growth of the discipline.

The first major research topic to be pursued was the characterization of eukaryotic DNA-dependant RNA polymerases, which to a group of biochemists represented the key enzymes for understanding transcription. Thereafter, the scientists focussed their efforts on the chromatin template and on resolving the nucleosome structure of DNA, which was proving to be an obstacle to the activity of these polymerases. In search of a more amenable experimental system, they were among the first groups to exploit the possibilities offered by the molecular revolution that marked the mid 1970s. Starting with the now simplistic idea of using recombinant DNA technology to isolate a well known "steroid controlled" gene, they fell upon the phenomenon of "split genes" and subsequently characterized exon-intron structures of eukaryotic genes. As these struc-

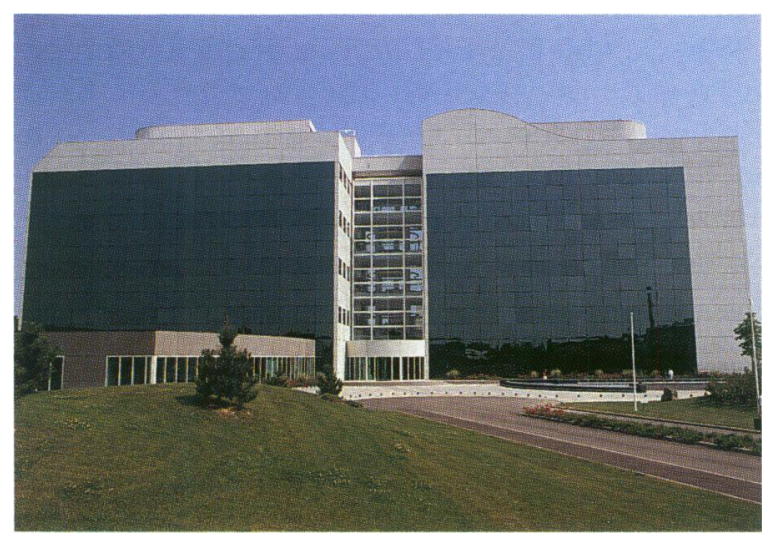

FIG. 1. Institut de Génétique et Biologie Moléculaire et Cellulaire (IGBMC), Illkirch Innovation Park, France

tural studies were in progress, by the beginning of the 1980s, the laboratory also started to focus on the $5^{\prime}$ or business end of the gene and made significant contributions to studies of both promoter and enhancer structure and function.

At the same time, the laboratory expanded and diversified its approaches with the establishment of new groups. First, there was a modest introduction of whole animal studies with work on invertebrate development in Drosophila, followed by the creation of a group working on human genetics, and finally mouse-based molecular immunology was added. In parallel, the biochemists started to purify the components of transcription complexes. The laboratory's studies of nuclear receptors blossomed in the second half of the 1980s. Initially, the in vitro and cell line approaches that had been so successful for studies of transcription factors were used. It was clear, however, that the complexity of the system would require a whole animal approach, 
and the next necessary expansion occurred in the direction of vertebrate embryology and mouse embryonic stem cell mutagenesis. Today, the laboratory has one of the largest collections of nuclear receptor "knock-out" mice and this technology has also been applied to other models of medical interest, notably to study genes implicated in the proliferation of tumors.

Although the continued expansion of the laboratory was scientifically justified, there was increasing pressure on research space in the Faculty of Medicine and, in a context where public spending on research institutes was in decline, a solution to this problem was far from obvious. Fortunately, the international status of our research groups was such that when, in the late 1980s, Squibb Pharmaceuticals decided to invest in French basic research, they became the basis of a novel agreement between private capital and public research agencies. Basically, Squibb (which became Bristol-Myers Squibb [BMS]) would construct a research center to accommodate these research groups and thereafter would participate with the public Centre National de Recherche Scientifique (CNRS), l'Institut National de Recherche Médicale (INSERM), and Strasbourg's University Louis Pasteur (ULP) in the running and research costs of the center. In practice, BMS participates by funding the research of a number of selected projects, while the remaining research groups have a free hand to obtain funding from national, European, and international programs, medically oriented charities, or indeed other industrial sponsors. While the IGBMC is increasingly aware of the potential application of its research to molecular medicine, the leitmotif remains the pursuit of scientific excellence in fundamental research. This philosophy can be summarized as, "You need to know how it works if you want to fix it."

Linked to the move to the new Institute was the decision to foster a number of young groups to complete the existing palette of models of animal development. Similarly, at the time of moving, the IGBMC strengthened its links with structural biologists with the group of Dr. Dino Moras joining the Institute. As we move into an era of molecular medicine by ligand design, structural biology is a critical element of the Institute's research capabilities and is already an integral component of a number of projects. With these additions, the IGBMC presently houses about 30 research groups and a total of 300 scientists and 200 associated research staff supported by the CNRS, INSERM, ULP, and the College de France.

In contrast to most French research laboratories, the number of tenured scientists is kept low (about a quarter of the total), ensuring the continual renewal of ideas. During their stay at the IGBMC, young scientists receive a broad training in the molecular techniques which are increasingly applicable to human health problems. The Institute itself was designed with an eye to the future rather than the present. In particular, laboratories were planned to be as flexible as possible, to accommodate changes in both techniques and in the research groups of the Institute. Personalized areas were kept to the strict minimum.

The IGBMC is a laboratory without doors. The twin central towers house four floors of research laboratories split into north and south wings separated by a glass walled atrium with its "coffee corners". The larger ground floor includes the library, a 200-seat lecture theater and the cafeteria, as well as the central administration, core facilities, and workshops. As designed by the California-based architect Ken Kornberg, the 63 standard laboratory modules are linked to the common technical spaces by a series of internal corridors that encourage a continual flow of people and ideas. This is essential, since despite the apparent differences in today's themes and model systems, the organization of genetic programs and the techniques for their study are shared features, and advances in both knowledge and techniques pass rapidly from group to group.

This philosophy of sharing is reinforced in practice by the emphasis on core service support in the Institute. The future of fundamental biological research, and by association of molecular medicine, lies in centers that can provide as complete a range of investigative techniques as possible. In the Institute, core services ensure DNA and peptide sequencing and synthesis, cell culture, monoclonal and polyclonal antibody production, the production and maintenance of transgenic animals, molecular hybridization and histology for light and electron microscopy, 3-D tissue reconstruction, bio-computing, etc. By drawing on these resources, a group at the IGBMC can be as competitive as one twice its size in a conventional institute.

With these exceptional research tools, the present and future research groups of the IGBMC are and will be equipped for the $21 \mathrm{st}$ century, which is foreseen as the golden age of molecular medicine. 